\title{
Application of Discrete Event Simulation in Mine Production Forecast*
}

\author{
F. A. Kaba, V. A. Temeng and P. A. Eshun
}

Kaba F. A., Temeng V. A. and Eshun P. A. (2016), “Application of Discrete Event Simulation in Mine

Production Forecast”, Ghana Mining Journal, Vol. 16, No. 1, pp. 40 - 48.

\begin{abstract}
Mine production forecast is pertinent to mining as it serves production goals for a production period. Perseus Mining Ghana Limited (PMGL), Ayanfuri, deterministically forecasts mine production which sometimes result in significant variation from the actual production. This paper developed an innovative stochastic discrete event simulation model to predict production for two excavators at a pit in PMGL site using Arena ${ }^{\circledR}$ Software. Time and motion studies of the shoveltruck system were conducted to build the stochastic model and production was predicted for four weeks. The results showed a total average production of $210414.86 \mathrm{BCM} \pm 3301.59 \mathrm{BCM}$ at $95 \%$ confidence interval. The total average production reflected a variance of $2.34 \%$ from the actual production of $215341 \mathrm{BCM}$. The deviation was low as compared to the deterministic planned production variance which was $5.44 \%$.
\end{abstract}

Keywords: Stochastic, Simulation, Deterministic, Production Forecast

\section{Introduction}

Mine Planning engineers forecast production to serve as targets during operations. This is normally done in surface mines by using deterministic approaches based on outputs of shovel-truck haulage operations (Sweigard, 1992).

Mining production forecasting at Perseus Mining Ghana Limited (PMGL), Ayanfuri, is not an exception to this; expected production is usually deterministically forecasted from mathematical relations with dig rates and availabilities of the excavators and trucks as input parameters (Sweigard, 1992 and Hustrulid et al, 2013). Besides the inability of this method to mimic the randomness of the activities of the shovel-truck system, results from this approach are prone to significant variation from actual production and budgeted production from the available fleet (Awuah-offei, 2015).

Consistent deviation from the mine plan whether positively or negatively has effect on the mine life and its economy. A consistent positive variation will shorten the mine life than planned and increase production cost. That of a negative variation will prolong the mine life and return fewer mineral commodities for the market (Abayie, 2001).

Variation in the plan production and the actual production is normally due to the variability in input variables of the shovel-truck system, ignoring inclement weather and other unexpected production hitches. To account for this variability, there is the need to develop a model that incorporates the dynamism and the uncertainty of the shovel-truck processes. Stochastic discrete event simulation allows the modelling of uncertainty and dynamic systems and it is also flexible in modelling various levels of detail and complexity (Awuah-Offei, 2012 and Awuah-Offei et al, 2012).

In this paper a stochastic simulation model is built with Arena ${ }^{\circledR}$ simulation software to forecast production at AG pit of PMGL. The model catered for the random behaviour of excavators and trucks in the pit and targeted a minimal variance between planned production and actual production.

\subsection{Mining Production Forecasting}

Mining production forecast is normally integrated into a short term operational plan of a mine. This is mostly done deterministically from mathematical relations with the input parameters stemming from the previous utilisations, availabilities and digging rates of the shovel-truck system (Sweigard, 1992 and Hustrulid et al 2013). Mostly, end of production week (scoping) meetings are organised for both mine planning and operations engineers to project average digging rates, availabilities and utilisations of the loading units used in the production. The mathematical relation involved in forecasting production per week for a loading unit in most surface mines as can be represented by equation 3.1 (Sweigard,1992 and Hustrulid et al 2013).

Production $=A x U \times$ Dig Rate $x$ Time

Where

$\mathrm{A}=$ availability of the loading unit (\%);

$\mathrm{U}=$ utilisation of the loading unit $(\%)$ 
Daily dig rate of the unit is measured in production units/time.

Usually, availabilities of the loading units are determined from maintenance schedules whilst the utilisation and dig rates are determined from past performances and foreseen digability conditions. Availability and utilisation are efficiency factors. These input parameters are normally determined from shovels only because haulage trucks are usually sufficient. Typically, there are standby trucks to replace any unscheduled breakdown trucks. Production therefore is much dependent on the activities of shovels.

\subsection{Arena ${ }^{\circledR}$ and its Applications in Mining}

Arena $^{\circledR}$ is a discrete event simulation software based on SIMAN simulation language. The software was developed by Systems Modelling Corporation and acquired by Rockwell Automations (Altiok and Melamed, 2007). The software is integrated with Visual Basic for Applications (VBA) so that further automation and programming can be done by users if specific algorithms are required (Anon., 2015).

According to Temeng and Oduro (2002) the modelling process in Arena involves the use of flow chart modules and data modules. Flow chart modules define the processes to be simulated while data modules describe the characteristics of various process elements, such as variables, resources, and queues. In the process of simulation, entities are created and as they move through the model they are acted on by the modules (Kelton et al., 1998).

Arena $^{\circledR}$ Software has been used in modelling shovel-truck systems, underground mining activities and metallurgical processes in the mining industry.

Awuah-Offei et al. (2012) built a stochastic model with Arena ${ }^{\circledR}$ to investigate the effects of using larger shovel, and optimising truck-shovel matching on fuel efficiency. A larger excavator was found to have increased the fuel efficiency of the operation while optimised truck-shovel matching did not reduce the fuel consumption rate.

A reliability model to confirm plant design capacity was also built with Arena ${ }^{\circledR}$ Software by Koenig et al. (2002). In the paper, surge capacities required between different sections of a manganese plant and critical equipment requiring standby capacity within the plant were evaluated. Also, the number of trains required for different sections of the plant, and potential capital cost reduction options were suggested.

Stochastic models of double drum cage and skip hoisting systems at Goldfields Ghana Limited,
Tarkwa were developed for performance appraisal (Temeng and Oduro, 2002). Various measures for improving the efficiency of the system were simulated.

Arena $^{\circledR}$ can also be integrated with other software such as Microsoft Excel and VBA to meet a desired need. Some other applications of the software both autonomous and/or integral have been reported in Pop-Andonov et al. (2012), Askari-Nasab et al., (2012), Torkamani, (2013), and Chinbat and Takakuwa (2009).

\subsection{The Shovel-Truck System of PMGL AG Pit}

Loading at the AG pit was done mainly by two Liebherr 9250 (EX 40 and EX 36) excavators in 5 $\mathrm{m}$ flitches and $10 \mathrm{~m}$ flitches depending on the type of material being loaded. Two Liebherr 984 excavators were used to supplement production in times of unscheduled breakdowns. EX 40 was matched with six trucks whilst EX 36 was matched with five trucks in a single back-up spotting configuration.

For each operational day which consisted of two shifts (9.5 hours day shift and 8.5 hours night shift), Trucks are loaded by shovels and material either hauled to crusher if it is ore or dumped at the waste dump if material is waste. Trucks travel empty back to their respective shovels in the pit after dumping and the cycle continues. There is a 30 minute break and all trucks are parked at assigned spots for convenience. The loading and hauling process continues after the break and lasts the entire duration of the shift. Trucks and excavators are essentially refueled and maintained after a mining shift in preparation for shift change over.

\section{Resources and Methods Used}

\subsection{Data Collection}

Representative data of the shovel-truck system pertinent to production were taken over a period of two weeks in January 2014. Time and motion studies were conducted on trucks assigned to EX 40 and EX 36. The following sets of data were taken for the modelling of the shovel-truck system:

(i) Loading time of trucks;

(ii) Hauling time of truck;

(iii) Spotting and dumping time of trucks;

(iv) Travelling time of trucks;

(v) Availabilities of EX 36 and EX 40; and

(vi) Production figures

The data were acquired by sitting in the cab of trucks assigned to the two shovels, after management and truck operators understood the 
nature and importance of the work. Data acquisition on each truck was changed after six to eight trips in order to obtain a representative data of the shovel-truck system. The representative data of trucks assigned to EX 40 was taken over 43 truck cycles while those trucks assigned to EX 36 was taken over 39 truck cycles.

\subsection{Data Analysis}

The data from the cycle times of trucks assigned to the two excavators were analysed with the Input Analyzer of Arena ${ }^{\circledR}$. Histograms of the representative data were plotted and graphs of best fit distributions were also superimposed on the histograms. Figs 1 and 2 show some of the plotted histograms of data sets from EX 40. Parameters and expressions as Arena ${ }^{\circledR}$ modules input data were calculated. The square errors between the theoretical distributions and the hypothesized distributions were also calculated.

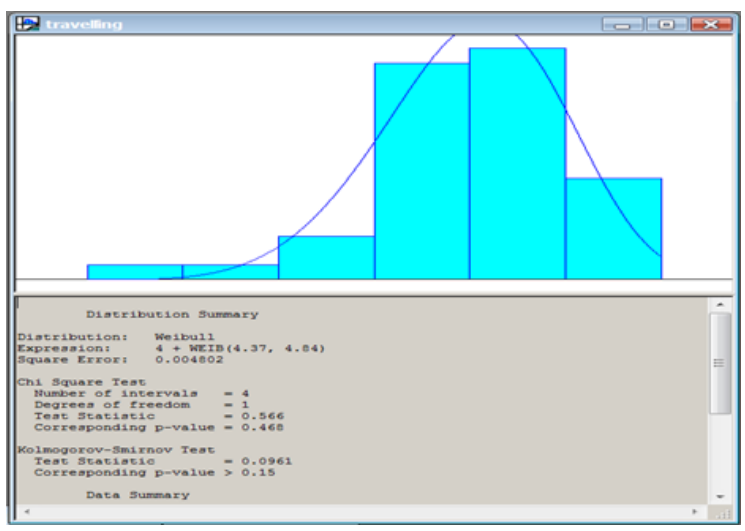

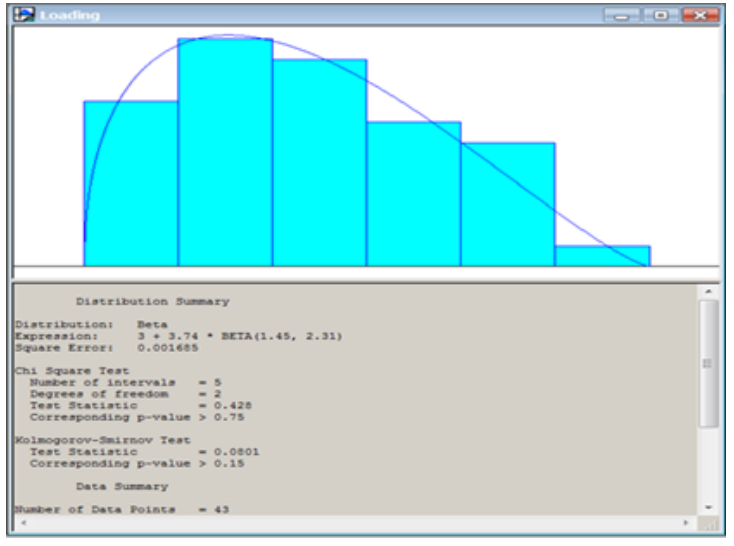

Fig. 2 Histogram of Travelling Empty (EX 40)

The goodness-of-fit tests employed by Input Analyzer are the Chi-squares test and the Kolmogorov-Smirnov test. The p-value at $5 \%$ level of significance is also applied in the hypothesis testing of the fitting of the theoretical distributions. The smaller the p-value is, compared to the 5\% significance level, the stronger is the hypothesis rejection; conversely, the larger the p-value is, relative to the $5 \%$ significance level, the stronger is the hypothesis acceptance (Altiok and Melamed, 2007).

A summary of the statistical distributions and the corresponding expressions used as Arena ${ }^{\circledR}$ input parameters for the simulation model is shown in Tables 1 and 2.

Fig. 1 Histogram of Loading Time (EX 40)

Table 1 Distributions and Expressions for Cyclic Activities of Trucks Assigned to EX 36

\begin{tabular}{|l|l|l|r|r|}
\hline \multicolumn{1}{|c|}{ Cyclic Activity } & \multicolumn{1}{|c|}{ Distribution } & \multicolumn{1}{|c|}{ Expression (in minutes) } & $\begin{array}{c}\text { Square } \\
\text { Error }\end{array}$ & $\begin{array}{c}\text { P-value } \\
\boldsymbol{\alpha}=\mathbf{5 \%}\end{array}$ \\
\hline Loading Time & Gamma & $2.54+$ Gamm $(0.113,7.44)$ & 0.004529 & 0.415 \\
\hline Hauling Time & Beta & $6.63+2.28 \times$ Beta $(1.51,1.24)$ & 0.016383 & 0.320 \\
\hline Dumping Time & Triangular & Tria $(0.55,0.963,1.1)$ & 0.020682 & 0.198 \\
\hline Travelling Time & Beta & $4.25+3.24 \times$ Beta $(1.84,1.69)$ & 0.011184 & 0.192 \\
\hline Travelling to Pit Park & User Defined & Continuous & & \\
\hline Travelling to Workshop & User Defined & Continuous & & \\
\hline
\end{tabular}

Table 2 Distributions and Expressions for Cyclic Activities of Trucks Assigned to EX 40

\begin{tabular}{|l|l|l|r|r|}
\hline \multicolumn{1}{|c|}{ Cyclic Activity } & \multicolumn{1}{|c|}{ Distribution } & \multicolumn{1}{|c|}{ Expression (in minutes) } & \multicolumn{1}{c|}{$\begin{array}{c}\text { Square } \\
\text { Error }\end{array}$} & $\begin{array}{c}\text { P-value } \\
\boldsymbol{\alpha}=\mathbf{5 \%}\end{array}$ \\
\hline Loading Time & Beta & $3+3.74 \times$ Beta $(1.45,2.31)$ & 0.001685 & $>0.750$ \\
\hline Hauling Time & Gamma & $8.34+$ Gamm $(0.672,5.15)$ & 0.011478 & 0.078 \\
\hline Dumping Time & Beta & $0.48+0.52 \times$ Beta $(2.11,1.87)$ & 0.014403 & 0.143 \\
\hline Travelling Time & Weibul & $4+$ Weib $(4.37,4.84)$ & 0.004802 & 0.468 \\
\hline Travelling to Pit Park & User Defined & Continuous & & \\
\hline Travelling to Workshop & User Defined & Continuous & & \\
\hline
\end{tabular}




\subsection{Model Formulation}

The shovel-truck system was modelled as a process where truck entities travelled from one station to another. Stations are conceptualised areas where resources act on entities moving through the system. Dumps, loading faces and parking areas are therefore considered as stations in the modeling process. A conceptual model of the process is shown in Fig. 3.

The Arena model approximated the dynamic and stochastic durations and statuses of the truck entities as they travel to and from stations.

The modelling was done by organising the modules of Arena into groups of trucks entity creation, shovel processes, truck entity movements, dumping processes, and break time decisions. These useful groups depicted the various major operations of the shovel-truck system.

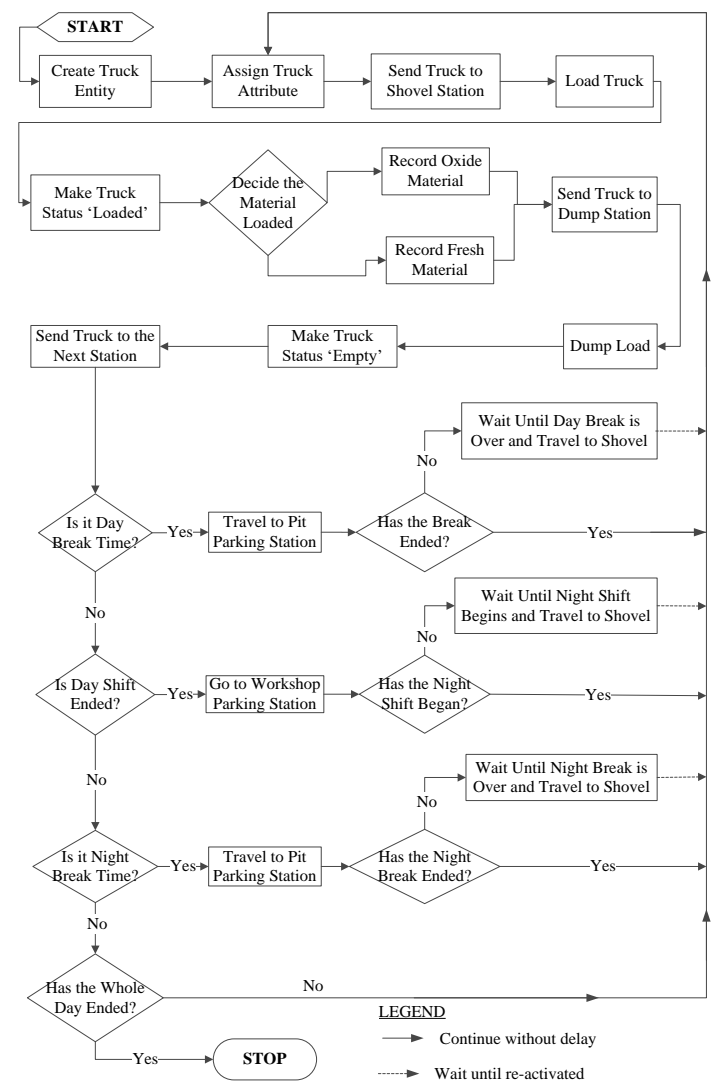

Fig. 3 Conceptual Model of Shovel-Truck System at PMGL AG Pit

\subsubsection{Trucks Entity Creation}

At the beginning of the simulation, portraying the beginning of a shift, two main groups of trucks assigned to EX 36 and EX 40 were created and matched with their respective shovel stations.
The Create module in the Arena ${ }^{\circledR}$ template was used to create trucks assigned to EX 36 and EX 40. The trucks then pass through a Decide module for them to be attributably assigned to their respective shovel stations.

\subsubsection{Modelling of Shovel Process}

Shovels were modelled as resources. The modelled shovel operation was such that a shovel seized one truck, delayed for a random loading time, and then released for the truck load to be recorded before it proceeds to a dumping station. The shovel modelling was based on the following practices (of the mine) and simulation assumptions:

(i) Blasted muck was adequate for excavators to mine for a shift;

(ii) Shovel loading time catered for all delays at the mining face

(iii) Mass excavation of ore and waste by excavators; and

(iv) The material can either be fresh or oxide.

A Process module was used to model shovel loading process and a Record module was used to record the loads carried by the trucks. A fresh material load was $35 \mathrm{BCM}$ whilst that of oxide material was $42 \mathrm{BCM}$.

\subsubsection{Modelling of Trucks Movement}

Trucks were modelled to move from one station to another depicting the reality of trucks moving from an excavator to a dump or from a dump to a parking station and/or from a parking station to an excavator. A travelling or hauling time is assigned to every truck that leaves a station to another. The following practices (of the mine) and assumptions of simulation were applied to model the trucks movement process:

(i) All trucks are similar in terms of their speeds;

(ii) The mine haul roads provide two-way-traffic for trucks;

(iii) Trucks were allowed to overtake each other i.e. pass each other (only in the modelling process).

A Route module was used to transfer the truck entities from one station to another at specified times. This transfer process depicts the travelling times from excavators to dumps and/or from dumps to excavators

\subsubsection{Modelling of Dumping Process}

Dumps like the shovels were modelled as resources and in such a way that each dump seized a truck, 
delayed it for a dumping time, and released the truck to travel from the dumping station to an excavator or parking station depending on the time into a day's operation. All dumps have adequate dumping capacities during a day's operation and a dump can only serve one truck at a time.

A Process module was also used in modelling dumping at dumps. The dumping times distributions were input in the delay time operand of the Process module.

\subsubsection{Break Time Modelling}

Operational breaks for lunch, change of shifts and night meal in a day's operation were modelled such that trucks parked at a particular place after dumping their material a few minutes to a break time as practised by the mine. The trucks were then batched and delayed for the break time to end before they were released to be separated and sent to their respective shovel stations within the Arena ${ }^{\circledR}$ model.

A Batch module was used to batch all the trucks to a particular parking station and then delayed to make up the break time by a Process module. The trucks were then separated into the respective truck assignments by a Separate module before they were sent to their respective shovel stations.

\subsection{Animation of the Shovel-Truck System}

Fig. 4 to 7 show the modelled process and the animation of the system in Arena ${ }^{\circledR}$. The various activities of the shovel-truck system were animated to ensure the visualisation of the whole operations of the mine with respect to the AG pit. A digital terrain model (DTM) representing AG pit was imported into Arena ${ }^{\circledR}$ for further drawings of haul roads, dumps and parking stations to be included. All routes animations were then digitised on haul roads to depict the movements of trucks. Shovel, dumps and queues in the forms of resource (if shovels and dumps) and queues in Arena animations were located at respective positions in the pit DTM and parking stations.

Truck entity picture was chosen as the default entity picture type in the modelling process. An Assign module was then used to change truck status to loaded and empty. A Route dialogue in the Animation transfer tool bar was used to animate haul roads. The Resource button in the Animation tool bar was also used to define shovels and dumps pictures for animation. Pictures representing idle and busy status for the shovels and dumps were also assigned.

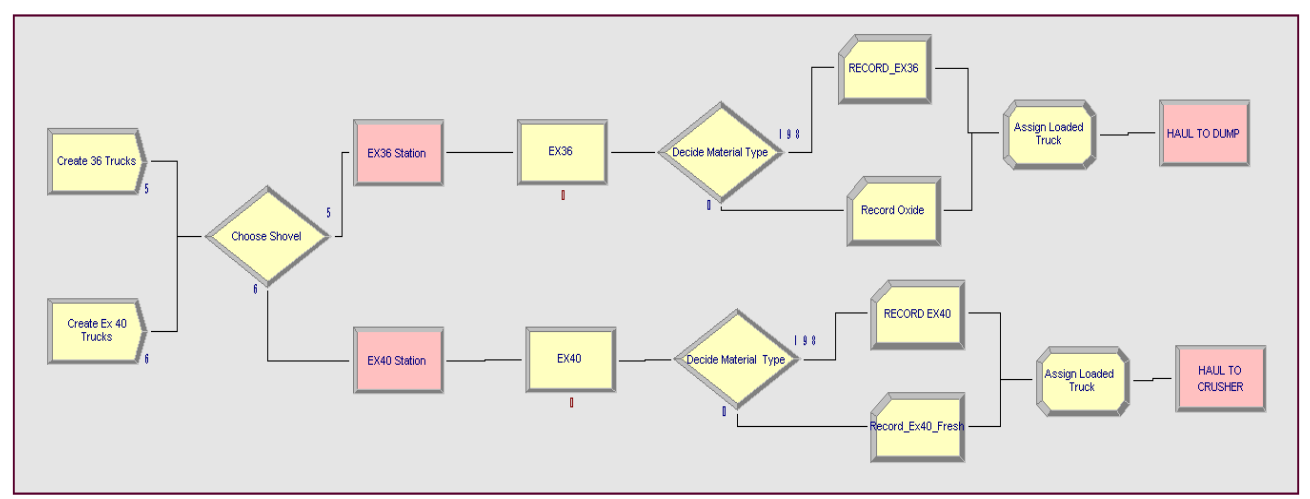

Fig. 4 Trucks Entities Creation and Shovel Processes

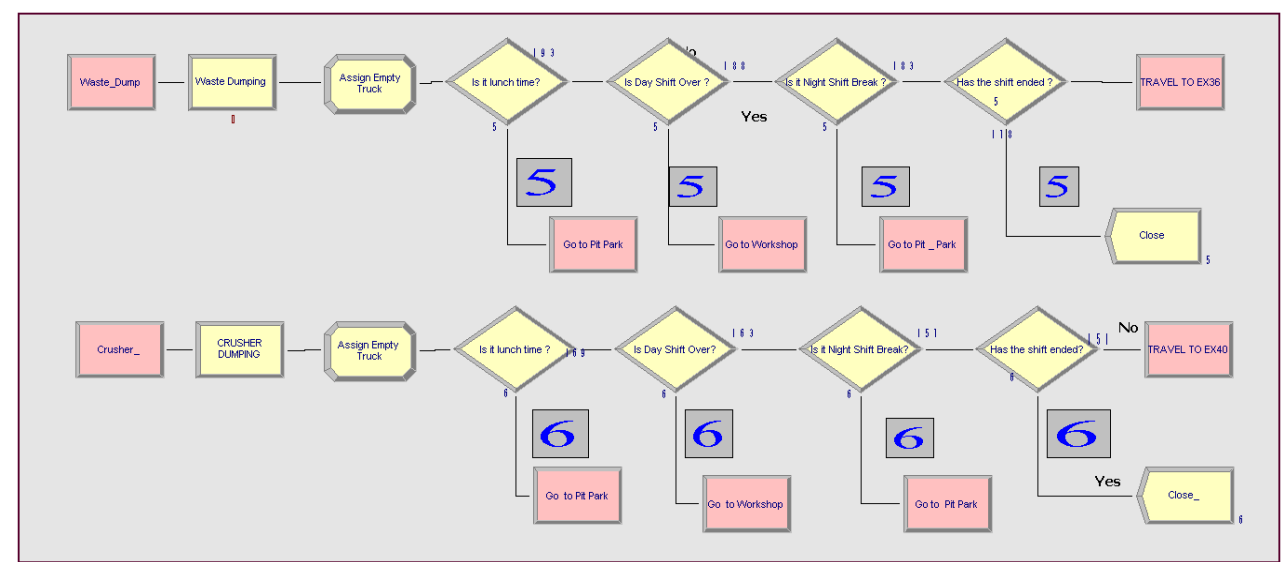

Fig. 5 Dumping Processes and Break Time Decisions 


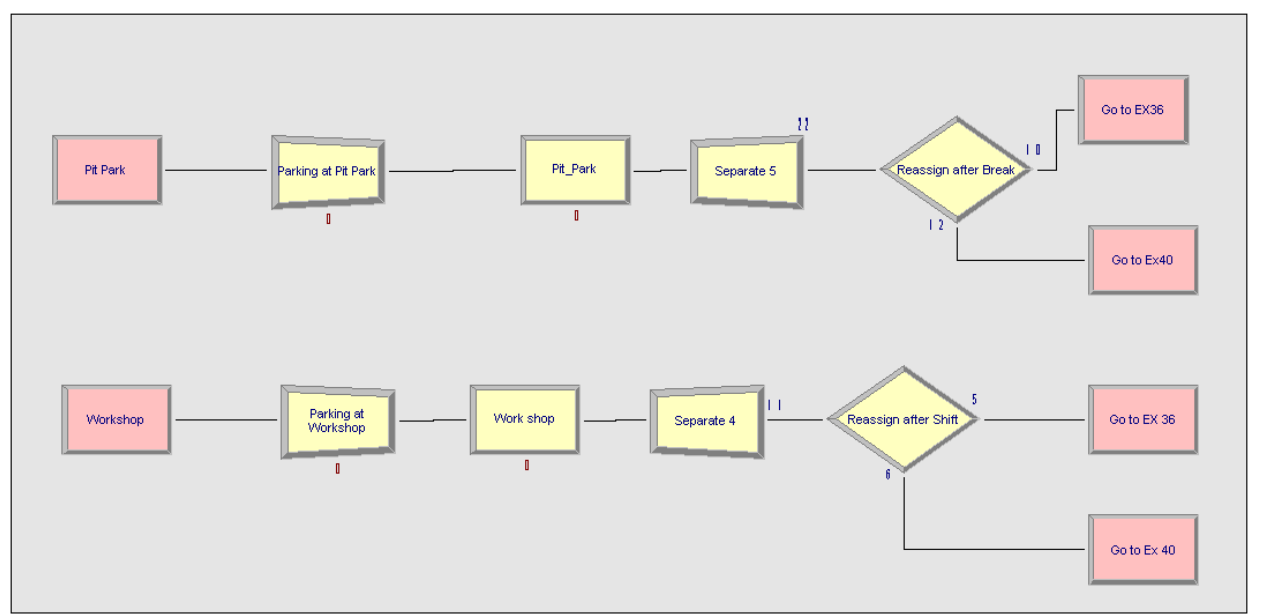

Fig. 6 Break Times Modelling

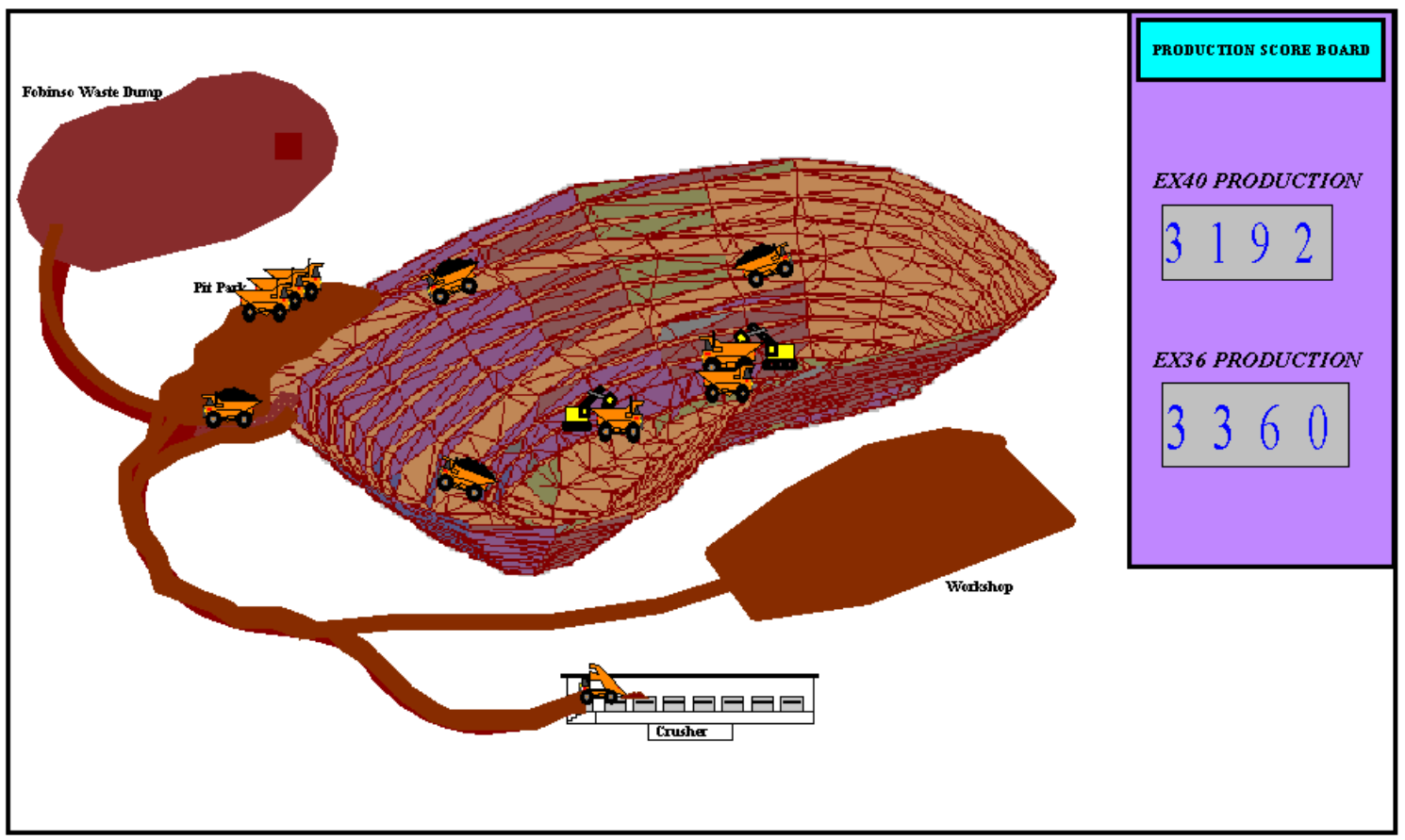

Fig. 7 Animation of the System in Arena ${ }^{\circledR}$

\subsection{Verification and Validation}

The model of the shovel-truck system was validated in the following ways:

(i) Truck entity movement within the modules were closely monitored during simulation to ensure that the trucks followed the correct direction at specified times. Synchronisation of transfer and delay (for loading, dumping or queuing) times were also followed.

(ii) The operations in the pit pertinent to the excavators and trucks were also animated on the DTM of the pit to ensure that trucks followed their specified direction and time. (iii) The model was also simulated for a whole day and the number of loaded trucks per shovel was counted to compare to the actual truck count of the shovel-truck system. Table 3 shows the results for the simulated truck counts and the actual truck counts.

Table 3 Results from Model Validation

\begin{tabular}{|l|c|c|c|}
\hline & Actual & Simulated & Error \\
\hline $\begin{array}{l}\text { Number of trucks } \\
\text { loaded by EX 36 }\end{array}$ & 194 & 196 & $1.03 \%$ \\
\hline $\begin{array}{l}\text { Number of trucks } \\
\text { loaded by EX 40 }\end{array}$ & 200 & 198 & $-1.00 \%$ \\
\hline
\end{tabular}




\subsection{Model Execution}

The model was executed using the statistical expressions of the various cycle time elements in Tables 1 and 2 as input parameters. The replication length of the model was calculated from planned weekly availabilities of the excavators, broken into daily scheduled down times. The model was then run on daily available time basis. Thirty (30) replications of the model were run for each day.

\section{Results and Discussion}

The total production in bank cubic meters (BCM) as well as production half widths at $95 \%$ confidence interval, from each of the excavators for each week is shown in Table 4. EX 36 was not available in week 1 hence its production was not simulated. Similarly EX40 production was not simulated because it was not also available in week 3. Table 5 shows the simulated average weekly production (BCM) from $\mathrm{AG}$ pit compared to the actual production (BCM) from the two excavators.

Results in Table 4 indicated that the total average production for week 1 was $41332.66 \mathrm{BCM}$. This was above the actual production with a variance of $4.70 \%$. The variance is not significant since taking into account the lower half width (at 95\% confident interval of $41158.92 \mathrm{BCM}$ will result in a lower variance of $4.10 \%$. Week 2 results also show variance of $7.03 \%$ below the actual production. This variance will also be decreased to $4.85 \%$ when the upper half width of the simulated production is considered.

Weeks 3 and 4 show minimal variance of $1.71 \%$ and $3.74 \%$ respectively below the actual productions for the two weeks which when the upper half widths are considered, the variances will be very minimal.

The total simulated average production for the four weeks is $2.34 \%$ below the total actual production. When the upper half width of $213716.45 \mathrm{BCM}$ of the simulated production is taken into account, the total variance between the simulated and the actual production will be reduced to $1624.55 \mathrm{BCM}$, representing $0.76 \%$ below the actual production.

Since the deterministic method is the existing method of forecasting production in the mine, the actual production was compared to the planned (deterministic) production as shown in Table 6. It can be seen that the deviations for Weeks 1 and 4 exceeded $10 \%$. The total simulated average production for the four weeks is $5.44 \%$ below the total actual production. This is more than twice the deviation given by the stochastic method.

Table 4 Simulated Weekly Production Results

\begin{tabular}{|l|c|l|c|c|c|c|}
\hline \multirow{2}{*}{ Week } & \multicolumn{2}{|c|}{ EX 36 } & \multicolumn{2}{c|}{ EX 40 } & \multicolumn{2}{c|}{ Total } \\
\cline { 2 - 7 } & $\begin{array}{c}\text { Average } \\
(\mathrm{BCM})\end{array}$ & $\begin{array}{c}\text { Half Width } \\
(\mathrm{BCM})\end{array}$ & $\begin{array}{c}\text { Average } \\
(\mathrm{BCM})\end{array}$ & $\begin{array}{c}\text { Half Width } \\
(\mathrm{BCM})\end{array}$ & $\begin{array}{c}\text { Average } \\
(\mathrm{BCM})\end{array}$ & $\begin{array}{c}\text { Half Width } \\
(\mathrm{BCM})\end{array}$ \\
\hline Week 1 & - & - & 41332.66 & \pm 173.74 & 41332.66 & \pm 173.74 \\
\hline Week 2 & 31710.94 & \pm 843.60 & 10700.67 & \pm 39.28 & 42411.61 & \pm 882.88 \\
\hline Week 3 & 46147.49 & \pm 113.79 & - & - & 46147.49 & \pm 113.79 \\
\hline Week 4 & 53501.47 & \pm 1476.51 & 27021.63 & \pm 654.67 & 80523.10 & \pm 2131.18 \\
\hline Total & $\mathbf{1 3 1 3 5 9 . 9 0}$ & $\mathbf{\pm 2 4 3 3 . 9 0}$ & $\mathbf{7 9 ~ 0 5 4 . 9 6}$ & $\mathbf{\pm 8 6 7 . 6 9}$ & $\mathbf{2 1 0 ~ 4 1 4 . 8 6}$ & $\pm \mathbf{3 3 0 1 . 5 9}$ \\
\hline
\end{tabular}

Table 5 Comparison of Simulated Productions and Actual Production in BCM

\begin{tabular}{|l|c|c|r|c|}
\hline \multicolumn{1}{|c|}{ Week } & $\begin{array}{c}\text { Average Simulated } \\
\text { Production (a) (in BCM) }\end{array}$ & $\begin{array}{c}\text { Actual Production } \\
\text { (b) (in BCM) }\end{array}$ & $\begin{array}{c}\text { Variance } \\
\text { (b-a) }\end{array}$ & $\begin{array}{c}\text { Variance } \\
(\%)\end{array}$ \\
\hline Week 1 & 41332.66 & 39473.00 & -1859.66 & $-4.50 \%$ \\
\hline Week 2 & 42411.61 & 45395.00 & 2983.39 & $7.03 \%$ \\
\hline Week 3 & 46147.49 & 46935.00 & 787.51 & $1.71 \%$ \\
\hline Week 4 & 80523.1 & 83538.00 & 3014.9 & $3.74 \%$ \\
\hline Total & $\mathbf{2 1 0 ~ 4 1 4 . 8 6}$ & $\mathbf{2 1 5 3 4 1 . 0 0}$ & $\mathbf{4 9 2 6 . 1 4}$ & $\mathbf{2 . 3 4 \%}$ \\
\hline
\end{tabular}


Table 6 Comparison of Planned Productions by the Mine and Actual Production in BCM

\begin{tabular}{|l|c|c|c|c|}
\hline \multicolumn{1}{|c|}{ Week } & $\begin{array}{c}\text { Average Planned } \\
\text { Production (a) (in BCM) }\end{array}$ & $\begin{array}{c}\text { Actual Production } \\
\text { (b) (in BCM) }\end{array}$ & $\begin{array}{c}\text { Variance } \\
\text { (b-a) }\end{array}$ & $\begin{array}{c}\text { Variance } \\
(\%)\end{array}$ \\
\hline Week 1 & 34560.00 & 39473.00 & 4913.00 & $14.22 \%$ \\
\hline Week 2 & 44000.00 & 45395.00 & 1395.00 & $3.17 \%$ \\
\hline Week 3 & 51410.00 & 46935.00 & -4475.00 & $-8.70 \%$ \\
\hline Week 4 & 74260.00 & 83538.00 & 9278.00 & $12.49 \%$ \\
\hline Total & $\mathbf{2 0 4} \mathbf{2 3 0 . 0 0}$ & $\mathbf{2 1 5 3 4 1 . 0 0}$ & $\mathbf{1 1 ~ 1 1 1 . 0 0}$ & $\mathbf{5 . 4 4 \%}$ \\
\hline
\end{tabular}

\section{Conclusions}

This paper aimed at developing a stochastic model that is capable of forecasting production to reduce the variance with the actual production. The model results had a deviation of $2.34 \%$ while the deterministic had a greater deviation at $5.44 \%$. The stochastic model predicted better due to its ability to incorporate the stochastic nature of the distinct processes of the shovel-truck system that result in production. The variability in the shovel-truck processes is always likely to cause much difference in what a deterministic formula will forecast and what will be actually achieved.

\section{References}

Abayie B. K. (2001), "Effective Approach to cost Management for Surface Mines in Ghana: A case Study of Sansu Surface Mine", Unpublished MSc Project, Kwame Nkrumah University of Science and Technology, Kumasi Ghana. Pp 140.

Altiok, T. and Melamed, B. (2007), Simulation Modeling and Analysis with Arena, Elsevier Academic Press, New York, USA, 440 pp.

Anon. (2015), "Arena (Software)", http:// en. wikipedia.org/wiki/Arena\%28software\%29, Accessed: February 20, 2015.

Askari-Nasab, H., Torkamani E., Badiozamani, M. M. and Tabesh, M. (2012), "Alignment of Short-Term and Operational Plans Using Discrete Event Simulation", Society of Mining, Metallurgy \& Exploration (SME) Annual Meeting, Seattle, WA, Preprint 12-064, pp. 18.

Awuah-Offei, K. (2015), "Can Discrete Event Simulation help you improve your Operation?", www.sphinxminingsystems.com/blog/? $p=78$, Accessed: January 14, 2015.

Awuah-Offei, K., Osei, B. and Askari-Nasab, H. (2012), "Improving Truck-Shovel Energy Efficiency through Discrete Event Modeling", Society of Mining, Metallurgy \& Exploration (SME) Annual Meeting, Seattle, W.A., Preprint 12-069, pp. 1-6.
Chinbat, U. and Takakuwa, S. (2009), "Using Simulation Analysis for Mining Project Risk Management", Proceedings of the 2009 Winter Simulation Conference, Rossetti, M. D. (ed.), Austin, Texas, pp. 2612-2623.

Hustrulid, W., Kuchta, M. and Martin, R. (2013), Open Pit Mine Planning \& Design, CRC Press, $3^{\text {rd }}$ Edition, New London, U.K, 1027 pp.

Kelton, W. D., Sadowski, R. P. and Sadowski, D. A. (1998), Simulation with Arena, McGraw Hill Publishers, $2^{\text {nd }}$ Edition, New York, 631 pp.

Koenig, R. L. Marinopoulos, N. and Olsson, B. R. (2002), "Using Reliability Modelling to Confirm Plant Design Capacity", Proceedings of Metallurgical Plant Design and Operating Strategies, Sydney, NSW, pp. 248-260.

Pop-Andonov, G., Mirakovski, D. and Despotov, Z. (2012), "Simulation Modeling and Analyzing in Underground Haulage Systems with Arena Simulation Software", International Journal for Science, Technics and Innovations for the Industry (Machines, Technologies, Materials), ISSN 1313-0226, pp. 48 - 50.

Sweigard, R. J. (1992), "Materials Handling: Loading and Haulage", In Chap. 9.3 of SME Mining Engineering Handbook, Hartman, H. L. (ed.), $2^{\text {nd }}$ edition, Vol. 1, SME, Port City Press, Inc., pp. $761-782$.

Temeng, V. A. and Oduro, A. K. (2002), “Analysis of a Mine Hoisting System Using Arena Simulation and Animation Techniques", Proceedings of Mine planning and Equipment Selection 2002, Kebo V. (ed.), Ostrava, pp. 509 - 514.

Torkamani, E. (2013), "Linkage of Truck-andshovel Operations to Short-term Mine Plans Using Discrete Event Simulation", Unpublished MSc Project Report, University of Alberta, Canada, 150 pp. 


\section{Authors}

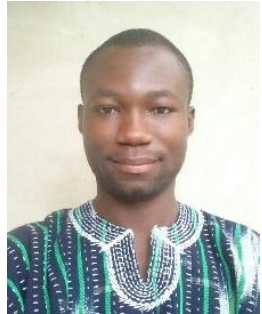

Kaba Felix Adaania is a Mine Planning Engineer at Newmont Ghana Gold Ltd, Akyem. He obtained his BSc in Mining Engineering degree from the University of Mines and Technology, Tarkwa, Ghana in 2014. $\mathrm{He}$ is a member of the Ghana Institution of Engineers (GhIE). Felix research interest lies in mine planning simulation of mining systems.

and design, and modelling and

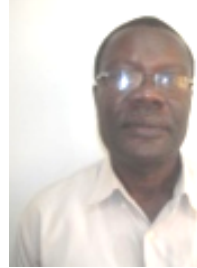

Victor Amoako Temeng is an Associate Professor in Mining Engineering at the University of Mines and Technology (UMaT), Tarkwa. He obtained his BSc (Hons.) and Postgraduate Diploma in Mining Engineering degrees from UMaT. He holds MSc degree from the University of Zambia and $\mathrm{PhD}$ degree from the Michigan Technological University. He is a member of the Ghana Institution of Engineers (GhIE). His areas of specialisation include simulation of mine production and equipment systems, Operations Research and Materials Handling.

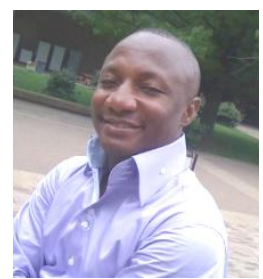

Peter Arroja Eshun is an Associate Professor in Mining Engineering at the University of Mines and Technology (UMaT), Tarkwa. He obtained his BSc (Hon), Postgraduate Diploma (PgD), MPhil and $\mathrm{PhD}$ degrees from the University of Mines and Technology in 1998, 1999, 2001 and 2011 respectively. He has been a lecturer at the Mining Engineering Department of UMaT since 2002. He lectures in Computer Applications, Alluvial and Ocean Mining, Mine Management, Mineral Economics, and Mineral Project Evaluation. His main research areas include mine finance and economic evaluation, socio-economic impact assessment and small scale mining. 